\title{
Qualitative analysis of virtual reality adoption by tourism operators in low-density regions
}

ISSN 1751-8806

Received on 27th February 2019

Revised 20th May 2020

Accepted on 16th July 2020

E-First on 28th October 2020

doi: 10.1049/iet-sen.2019.0038

www.ietdl.org

\author{
José Martins ${ }^{1,2,3} \bowtie$, Ramiro Gonçalves ${ }^{2,3}$, Manuel Au-Yong-Oliveira4, Fernando Moreira5,6, Frederico \\ Branco 2,3 \\ ${ }^{1}$ Instituto Politécnico de Bragança, Campus de Santa Apolónia, 5300-253 Bragança, Portugal \\ 2INESC TEC and UTAD, Vila Real, Portugal \\ ${ }^{3}$ AquaValor - Centro de Valorização e Transferência de Tecnologia da Água, Chaves, Portugal \\ ${ }^{4}$ Department of Economics, Management, Industrial Engineering and Tourism, GOVCOPP, University of Aveiro, Aveiro, Portugal \\ ${ }^{5}$ REMIT, IJP, University Portucalense, Porto, Portugal \\ ${ }^{6}$ IEETA, University of Aveiro, Aveiro, Portugal \\ 凶E-mail: jose.I.martins@inesctec.pt
}

\begin{abstract}
Virtual reality technologies have grown in complexity and functionality, increasing their relevance in various sectors of activity. Applying these innovations to tourism is advantageous for the organisations, the tourists and even the territories. They can provide multisensory immersivity, simulate actions and movements in real-time, enriching reality using interactive virtual objects. Thus, captivating visitors and showing territories from richer and livelier perspectives. This study describes a review of the adoption of virtual reality technology at the organisational level. In order to adapt the literature review to the tourism topic, the process of analysis of the literature was carried out with a constant concern to analyse research that studied the topic. Assuming the need to further develop the work done and to obtain a confirmation on the contribution resulting from the bibliographic review, a focus group was developed, which allowed several specialists to discuss collaboratively and interactively the research project topics without having to be in face-to-face contact. The results of this study allow not only to acknowledge the relevance of virtual reality for tourism but also to understand how the existing literature and experts are aligned with the identification of opportunities for disruptive development of solutions that trigger tourism destinations and organisational development.
\end{abstract}

\section{Introduction}

Tourism has gained considerable prominence in recent years, becoming an activity of vital relevance for the economic sector in several countries [1]. Portugal is no exception, both for tourism in the coastal areas and large metropolises, as well as tourism associated to the underdeveloped and rural regions, thus being one of the countries with the largest balance of tourism in the European Union [2].

By using technology, it is possible to improve management processes, promote products and services and more effectively respond to customer needs through increased personalisation, dynamics and innovation. Hence, an aim is to trigger the interest and immersion factors in the tourism experiences that tend to result in higher customer satisfaction [3]. In what concerns tourism, the incorporation of technology is considered to be something that might imply potential high impacts for organisations, tourists and territories alike [4].

One of the technologies being currently applied to tourism initiatives is virtual reality (VR) [5]. This technology allows to provide virtual and immersive experiences, that might even include multisensory environments, where users can simulate actions and movements in real-time [6].

The objectives of this study are two-fold. First, the focus is on identifying and characterising the possible set of determinants of VR adoption by tourism operators in economically disadvantaged regions. Therefore, a systematic review of the literature in the field of adoption of the research technologies, namely VR in the tourism sector, was performed. Second, it is our objective to validate the adequacy of VR as a valid support for tourism initiatives [7].

We start this paper by presenting an overall perspective on both the research focus and the posed objectives. This initial section is followed by an overall description of the adoption of information technologies (ITs), the importance of adoption models and their relevance at the firm level. In order to focus our research, we present a brief conceptualisation on low-density regions and their tourism activity. In Section 4 we present the set of possible determinants for VR adoption by tourism operators in low-density regions. Next, in Section 5, we continue with the description of the focus-group activity performed with the goal of validating our research results and assumptions. We finalise our paper with a set of overall conclusions and final considerations.

\section{IT adoption at the organisational level}

ITs have evolved significantly in recent years, becoming increasingly important and present in society. IT is capable of revolutionising limits and structures both at work and in society itself, presenting themselves as an added value in the business sector [8]. IT use has a strategic character related to the market, since it is increasingly a competitive factor and of functional essence, enabling the expansion of productivity levels and an improvement of management and interaction processes [9].

IT is seen as an essential product, both by individuals and organisations, as they allow businesses to grow. Furthermore, IT triggers innovation, and ensure organisational growth, greater efficiency and better positioning in market rankings [10].

IT adoption at the corporate level provides for an improvement in the quality of the products and / or services, thus allowing, through efficiency gains, process automation, better business performance and greater management efficiency, to respond to customer needs in a more accurate manner [11].

Albeit, as the literature argues, the implementation of these technologies at the organisational level has always been associated with both internal and external determinants [12]. At the internal level, the inherent characteristics of each organisation, the use and 
utility of each technology and its interaction effects are always pointed out as being relevant. From an external perspective, organisational beliefs, attitudes, employees and management opinions and posture, as well as a series of existing external pressures, tend to influence the adoption of a given technology [13].

As argued by Wu and Chiu [14], a given innovation can be classified as one of three types, according to its application and objective

(i) It is linked to the acquisition of services and products that assist in administrative and organisational tasks.

(ii) It refers to those innovations aimed at supporting those in management, concerning their decision-making.

(iii) It encompasses innovations focused on giving competitive advantages to those who adopt it first.

The implementation of any technology at the organisational level requires those who are responsible for the implementation process, to be aware of both the organisational characteristics and the changes inherent to the adoption process. Typically, adopting a new technology requires a fair amount of reconfiguration and organisation as well as task planning [15]. For instance, employees need to be familiar with the technology and hold a positive perception of its adoption results, ease of use and perceived benefits, in order to ensure the successful development of business initiatives supported by it [16]. The motivation to use and the commitment to the expansion of knowledge and the existence of practical capacities on how to use a given technology are essential for reducing the complexity associated with its use. The users' values and beliefs about the functioning, performance and ease of the system are also factors to be considered [17].

According to Cardoso, et al. [18], IT allows for the creation of sustainable competitive advantages by helping organisations to solve problems and develop new business strategies, hence creating differentiation and improving the tasks performed within the organisation, by changing the way they are carried out.

On the other hand, as one can imagine, the adoption of technology is not without risk, investment needs and operational costs. These concerns are very relevant for small and medium enterprises given that their own (more limited) nature with scarce resources tends to enforce for increased caution when analysing and incorporating new technologies in their business initiatives [19, 20].

In order to minimise risks, it is necessary to reflect on the benefits coming from the use of ICT for operability, management effectiveness, competitive advantage, availability of new resources and the cost of hardware and software. Furthermore, the socioorganisational context, the needs, the development of a strategy to face barriers intrinsic to the change, the characteristics of the CEOs and the experience of the employees play an important role [21].

\section{Tourism in low-density regions}

The tourism industry is among the main business sectors of economic activity worldwide and is considered to be one of the most relevant economy engines for certain countries. Moreover, it is also considered one of the most important economic activities for regions where social and economic development are lower than the national average [22].

Tourism creates jobs in the most varied companies, such as in catering, lodging, transport and travel agencies, tour operators, shops, drivers, as well as allowing for the development of companies, improving infrastructure, and maintaining the environment through the creation of National parks, protected areas and natural attractions. Tourism also promotes dialogue and interaction between different civilisations and cultures, cultural and social events and the conservation of local cultural heritage [18, 23].

As time goes by, tourism-related services and products are becoming increasingly diversified, sophisticated and specialised to meet the needs and desires of consumers. For this to be possible, tourism agencies must have access to accurate and timely information and knowledge in order to be able to define the best policies and strategies for a given tourist destination and in order to have better management and planning. It is very important to know the supply, the tourist demand and the effects at the environmental, socio-cultural and economic levels in the different regions to make them more attractive and desirable to visit [4].

\subsection{Digital transformation in tourism}

The sustainable development of tourism (and of its inherent businesses) is becoming a competitive activity where any innovation is of the utmost importance for the promotion and sale of products that fulfil tourist requirements and needs [24].

Representing in a unique and faithful way the different tourism destinations and doing so by creating relevant information that at the same time accurately describes the destination and, in parallel, attracts customers is becoming extremely complicated. Tourists are becoming more sophisticated, demanding and wishing for higher quality products. Hence, market competitiveness is increasing, which forces organisations to add more value in a more conscious way. Companies need to be aware of the smallest innovation in order to maintain their position regarding consumer preferences and so as to increase their visibility [25].

The digital transformation in tourism has allowed for the creation of new business models, more and better opportunities, a more efficient service, new offerings and faster responses to tourists [26]. Therefore, the use of IT has contributed greatly to the obtaining of more accurate and reliable information, helping decision-making, enriching experiences and increasing interactivity between companies and consumers $[20,27,28]$.

The use of the Internet and the rise of the internet of things (IoT) have triggered tourism organisations' connectivity and innovation, thus allowing for added communication and cooperation between destinations and users, making territories and tourism points-of-interest an integral part of the Internet [29]. Moving this concept to an urban context is of great interest because it would respond to the needs of tourists as well as national governments who aim at integrating tourism organisations, territories and tourists.

Smart tourism and smart tourism destinations (STD), extrapolations from the smart city concept, are the new reality of tourism. They are characterised by the transversal use of information, communications and electronic technologies embedded in all existing organisations and points-of-interest, thus allowing destinations to develop enriched tourist experiences [30]. The systems built under the smart tourism or STD concepts are based on trust, scalability and openness towards participants and services [31]. From a more practical perspective, when technological infrastructures are implemented in an STD, they tend to ensure the sustainable development of the tourist areas, creating accessibility features that allow access to all and facilitate visitor interaction, while also promoting the quality of the experience and the life of the residents [32].

\subsection{Tourism in low-density regions}

According to the purpose of the trip, the type of tourism is defined. When the trip provides direct contact with nature, local traditions and it is in a rural and familiar environment, it is called rural tourism. This type of tourism stimulates regional economic activity, regarding agriculture, handicrafts, catering, service sectors and local products, and contributes to socio-cultural development [33].

Low-density regions are characterised as having a small population, low-social and economic development, reflecting lowpurchasing power and a constant decrease in the number of the resident population [18]. These regions have an increased interest in their mystique, history, culture and they are qualified as spaces of great environmental quality for the richness of the landscapes that nature offers [34].

Using IT is as important for organisations as it is for developing territories. It is possible to combat desertification, a lack of investment, a lack of knowledge of certain areas, economic problems, the maintenance of local services while promoting 
greater social contact in isolated communities by carrying out tourism activities in these areas. With the growth in the number of tourists, so do local business opportunities and jobs increase, in addition to promoting their own cultures [35]. Thus, the growth of tourism in areas that do not have the necessary potential to maximise their indicators (economy, population, businesses etc.), is vital $[36,37]$.

The development of rural tourism has been stimulated by new policies and measures to combat depopulation and to trigger the sustainable development of the inherent rural areas, both through economic diversification and through the exploitation of endogenous resources $[38,39]$.

\section{Virtual reallty as a tourlsm trigger}

\subsection{Application of the virtual reality to tourism}

VR is used as an interface for the user and as an application system, creating a virtual environment that can be moved and manipulated in real-time. VR generates synthetic three-dimensional environments via computers, which can be immersive if the user immerses himself/herself in the created scenario [40].

The use of VR technology offers advantages in what refers to business strategies, as it provides digital (and virtual) experiences with improved quality, diversity and utility. In the tourism sector particularly, it is possible to improve the experiences of tourists and to help organisations to add value to their products as well as increase their sales [41]. VR content can be more attractive and complete, since access to valuable information and increased knowledge about a particular destination or attraction can be highlighted and thus noticed [4]. These technologies might assist tourism organisations and institutions in the promotion of points of interest and in the addition of extra information that can be used to enhance the discovery of monuments, places or points of attraction, as well as hotels, and all of this while drawing on the preferences of the individual $[42,43]$.

VR can also be implemented in museums or in cultural heritage sites [44], to attract more visitors and to enhance their experience. By adding value to an experience, whether it is a visual prop, an entertainment feature, a pleasure or even knowledge trigger, the tourist exposition becomes more interesting [45]. Hence, the implementation of VR solutions has the potential to reshape the design of exhibitions and the very environment of museums, influencing the attention of visitors [46].

To implement this technology in unexplored areas in order to increase their interest, to develop and promote new tourism destinations, to provide interactive cultural and heritage experiences, as it can take the history of the place to the tourist, contributes to the safeguarding and recognition of territories and of particular regions' cultural heritage [47].

\subsection{Determinants of the virtual reality adoption}

With the objective of helping tourism organisations to consider the implementation of $V R$, an effort has been expended towards analysing the existing literature on the adoption of VR, augmented reality, mixed reality and other similar technologies and systems.

According to Keele [48], an adequate literature analysis should encompass three main stages: (i) a first stage where the authors should define what might be the research questions to which the literature should try to provide an answer; (ii) a second stage where the search and refinement criteria should be defined and (iii) a final stage where authors should formalise, in writing, the results of their efforts.

Hence, drawing on the previously mentioned methodology, we defined the following research questions that would serve as the basis of the literature analysis process:

- What is the current perspective on the adoption of VR technologies at the firm level?

- Which determinants might be considered when characterising VR adoption at the firm level?
- Which determinants might be considered when characterising VR adoption by tourism operators, particularly by those in lowdensity regions?

- What are the determinants, already considered as triggers to the adoption of other ITs, which might be considered VR adoption determinants?

After defining the research questions an effort has been made to specify the list of primary search terms that would serve as the basis for our literature analysis. Thus, the following terms have been used as the basis of our research: 'VR adoption', 'AR adoption', 'VR tourism', 'low-density tourism', 'tourism digital transformation' and 'IT adoption'.

The literature analysis lasted for a period of 90 days and focused on research published in scientific repositories (ex: ACM Digital Library, IEEE Xplore Digital Library, Web of Science, ScienceDirect, SCOPUS, Springerlink, Wiley Interscience Journal Finder and IET Digital Library) and an effort was made to privilege journals from Thomson JCR first and second quartile and level A and B CORE conferences. After initially converging towards the referred types of publications, we then completed our analysis with Thomson JCR third and fourth quartile journals and scientific conferences not indexed by CORE.

The results from this effort have been represented in Tables 13, where one can perceive not only the identified (possible) determinants of VR adoption but also a brief characterisation of the inherent concept.

In accordance with other similar studies focused on the adoption of information and communication technologies, all identified determinants have been organised according to their context: (i) technology - those determinants that are directly related to VR technologies; (ii) organisations - those determinants that are related to the organisational context and with the characteristics of the organisations and (iii) environment - those determinants that are inherent to the organisation's external environment and location.

Despite the overall value of the presented set of possible VR adoption determinants, and drawing on Martins et al. [55], a decision was made to perform a qualitative assessment of both the achieved determinants and of the overall assumption that VR technologies might be a valuable technology for tourism and in particular for tourism in low-density regions.

\section{Focus group analysis}

After performing an attentive analysis of the existent literature (presented in the previous section), a qualitative study has been performed not only to validate our initial assumptions on the digital transformation of tourism but also to validate the results from the literature analysis that has been completed.

\subsection{Conceptual perspective}

As argued by Nunes et al. [56] and Gonçalves et al. [84] the collective and collaborative understanding of a research topic is essential for its development as it tends to be supported by an active and interactive discussion between experts whose experience and knowledge foster the emergence of new and more interesting perspectives.

Even though the focus group method is associated with the social sciences, multiple (and successful) efforts have been performed to adapt it to the exact sciences such as computer science [85]. A focus group involves the combination of experts in a particular field of study, for an open and detailed discussion on a given topic [86].

Over the last few years, the incorporation of digital technologies as a mechanism for streamlining the execution of the method, has been a common practice. This digital version of the initial research method goes by the concept of 'online focus group' $[87,88]$. From a practical perspective, this new version allows for interactive and highly collaborative interactions between all the focus group experts that can happen remotely and in both synchronous and asynchronous manner [39]. 
Table 1 Technology-related determinants that might be associated with the VR adoption that were identified during the literature analysis

\begin{tabular}{lc}
\hline $\begin{array}{l}\text { Variables } \\
\text { perceived } \\
\text { usefulness }\end{array}$ & $\begin{array}{c}\text { the degree in which the organization believes that using VR would allow for achieving gains and thus improving its } \\
\text { business model. As a result, the existing literature tends to pose perceived usefulness as a positive influencer of } \\
\text { behavioural intention to use innovations and disruptive technologies such as VR }\end{array}$ \\
$\begin{array}{r}\text { technology price } \\
\text { in a time where organizations are enforced to strongly control their financial situation and make decisions oriented } \\
\text { not only towards potential profit/improvement but also to business sustainability, the price of a given technology } \\
\text { might represent a strong determinant of the adoption decision. Considering the current high price of both VR } \\
\text { technologies as well as of content creation services, this factor will surely make a decisive contribution to the } \\
\text { organizational decision towards VR adoption. This situation may even be critical in smaller organizations focused } \\
\text { on the tourism sector, in regions with lower economic value }\end{array}$
\end{tabular}

security perception the incorporation of a novel technology tends to trigger a sense of insecurity in organizations, particularly regarding those who lack the ability to implement full-spectrum security measures that prevent problems. Adding to this, the most recent legal regulations on data security and privacy have also created a concern for the organizational environment. Hence, considering the innovative aspect surrounding VR, it is important to understand the impact that the perception on how robust, from a data security perspective, the adoption of the referred technology might have to be

trust

when considering incorporating new technology, organizations tend to analyse the impact it might have in relation to the overall organizational performance and efficiency. Thus, in line with the existing literature, when considering VR systems, it is important that organizations trust the technology and are ensured that it will not have a negative impact on their overall performance

compatibility incorporating a novel technology is something that represents a considerable amount of risk for an organization. Hence, there is a tendency to analyse the adequacy of the referred technology with existing business processes, values, experience and needs. Thus, when considering the adoption of VR, organizations should endure an analysis of the compatibility between the technology solution and its business processes

trialability

if a given technology is extremely innovative, organizations tend to prefer to perform some initial and internal trials in order to perceive if the technology has the ability to improve their overall performance. Hence, when addressing VR systems, it is important to perceive the degree in which its trialability might be considered as a trigger for adopting it

perceived value of when adopting a given technology, organizations undergo a focused analysis of the difficulties associated with VR incorporating the technology in their daily activities, and on the benefits that might be achieved due to using the referred technology. Hence, the perceived value of VR might be considered to be the subjective trade-off between the technology complexity and inherent difficulties and the prospective benefits associated with using the technology

VR content quality the development of VR systems and applications must be done while remaining concerned with content quality. Considering that, as argued by the existing literature, the user experience has a significant dependence on the quality of the presented content, we posit that the ability to develop high-quality content for VR systems and applications might represent a positive trigger towards the adoption of this technology

VR system quality in order to consider adopting a given technology, organizations must be ensured that these are robust, have the ability to perform and are reliable. When addressing the novelty associated with VR, we hypothesise that the quality level of VR systems and applications might be considered a determinant for the adoption of the technology. When the presented systems or applications are perceived to be of high-quality, users tend to appreciate the VR experience even more

VR service quality the existence of a support service that helps organizations to implement their technology-based initiatives is considered by the existing literature as a positive trigger towards the incorporation of technological innovation. Hence, when considering the specificity and complexity associated with VR, it is our belief that the existence of high-quality support services that help organizations to plan and implement VR-based initiatives might represent a positive trigger towards the adoption of that technology

VR system personalization considering the complexity behind the majority of disruptive information and communication technologies, there is a tendency for organizations to require that these have the ability to be customised to their own reality. Hence, as VR is an incredibly complex technology, it is valid to enquire the degree of personalization of VR systems and applications and how this will affect the adoption process

interoperability

the amount of technology-based systems and applications that organizations already use is extremely significant.

Hence, when considering the adoption of novel technology such as VR it is important for organizations to understand the degree of interoperability between VR-based systems and the remaining systems and organizations that the organization has already incorporated into its business model

complexity

highly complex systems and applications may give rise to difficult adoption processes. As VR solutions tend to have $[55,56]$ a considerable degree of complexity it is possible that this issue might represent a problem

standardisation level of standardization of VR technologies. When a given technology has been the focus of standardization and certification processes, organizations are prone towards adopting it

perceived ease of it relates to the degree to which an organization believes that using VR technologies, systems and applications is easy

\subsection{Online focus group characterisation}

The second component of our research relies on the execution of an online focus group, which was composed of nine experts from different areas: VR systems and technologies, tourism, management, research and monitoring, and municipal and regional coordination. The main goal of the abovementioned interaction and discussion was to reach some sort of overall alignment between the experts' opinions on two acknowledgements that have already been reached during the previous execution of our research: (i) the worldwide tendency for the digital transformation of tourism, including ICT, in particular, in low-density regions and in regions 
Table 2 Environment-related determinants that might be associated with the adoption of VR that were identified during the literature analysis

\begin{tabular}{|c|c|c|}
\hline Variables & Description & Ref. \\
\hline consumer readiness & the level of readiness and inclination for the user to accept VR (ability, preparation and attitudes) & {$[66,67]$} \\
\hline perceived tourist benefits & the level of benefits that VR systems and applications might bring to tourists & {$[59,65]$} \\
\hline normative pressures & $\begin{array}{l}\text { the existence of norms and regulations that enforce or limit the development of business initiatives supported } \\
\text { by VR technologies might act as an influencer of the technology adoption process }\end{array}$ & {$[68,69]$} \\
\hline environment pressure & $\begin{array}{l}\text { the level of pressure brought about by the competition in the industry and the strategic needs to compete in } \\
\text { the market }\end{array}$ & {$[70,71]$} \\
\hline physical location & refers to the geographical location of the organization & {$[18,72]$} \\
\hline
\end{tabular}

Table 3 Organization-related determinants that might be associated with the adoption of VR that were identified during the literature analysis

\begin{tabular}{|c|c|c|}
\hline Variables & Description & Ref. \\
\hline attitude towards using & level that quantifies the favourable attitude that the users present in relation to the use of VR & {$[65,73]$} \\
\hline behavioural intention to use & level of intent that users present to use VR & {$[57,74]$} \\
\hline $\begin{array}{l}\text { perceived organizational } \\
\text { benefits }\end{array}$ & related to the advantages or perks that the organization will have with the use of VR & {$[70,75]$} \\
\hline privacy & related to the confidentiality of data used by the VR systems and applications & {$[65,76]$} \\
\hline $\begin{array}{l}\text { organizational } \\
\text { innovativeness }\end{array}$ & $\begin{array}{l}\text { level that quantifies the capacity to change and promote creativity and innovation that the organization } \\
\text { possesses }\end{array}$ & {$[62,77]$} \\
\hline decision-makers' & related to the knowledge and innovative capacity of the decision makers & {$[66,67]$} \\
\hline
\end{tabular}

knowledge

top management support

the level of influence that the administration applies to the promotion and support of VR business initiatives the level of IT adoption and the number of IT elements within the organization

[55]

intensity of IT adoption

absorptive capacity

permission level for the organization to acquire, assimilate, transform and exploit knowledge and promote

[78] change

experience

firm size

level of knowledge and experience with VR

$[58,79]$

related to the number of employees and the financial and human resources that the organisation presents. [55, 70$]$ The greater the number, the easier the implementation of new technologies

culture degree of influence that the beliefs, values, habits, norms and behaviour patterns have on the group of $[51,71]$ workers in the organisation

age of firm

observability

industry

employee support

knowledge sharing

perceived satisfaction

readiness

years the company has existed

$[51,67]$

a level at which the results of VR adoption are visible to others

$[73,80]$

it refers to the sector that the organisation belongs to

$[34,66]$

level of employee willingness towards using VR systems and applications

$[52,53]$

level of knowledge sharing by members of the organisation. The existence of a knowledge-sharing culture [68, 81] tends to trigger innovation adoption

the degree of satisfaction that both users and organisation present for a given VR solution at a given time [49, 82] level of readiness that the company possesses, both at the technological level and at the strategic level $[70,83]$ and including technical skills and partnerships

CEO characteristics

behaviour of the CEO when using a given VR solution: the degree of capacities, confidence and innovation

technology infrastructure

level at which an organisation believes that VR technologies are necessary for implementing innovative and disruptive initiatives

with low-economic and social development and (ii) the possible relevancy of the previously identified determinants of the VR adoption process.

The focus group of experts (Table 4) involved individuals with a significant level of academic qualifications (at the undergraduate, master's and doctoral level), people who are professionally integrated with the three main sectors of activity (academic, public administration and private companies) and have more than five years of professional experience or specialisation.

After receiving an email containing the explanation of the focus group context and inherent goals, the experts accepted the invitation to give their opinion on the process regarding the digital transformation of tourism and its impact on territories (in particular in low-density regions). Additionally, views were given on the inclusion of disruptive technologies, such as VR, with the intention of operators and the territories developing a more integrated and innovative tourism offer. This acceptance was then formalised with a written, informed and signed consent.

Throughout the process, all the interactions and comments of the participants were recorded to make it possible to reach a set of global and representative considerations of the group's global perception.

\subsection{Focus group execution}

Drawing on Vaportzis et al. [89], moderators sent an initial message to all experts containing a global overview of the research that was being done (i.e. the focus group is perceived as an initial stage of a broader study that will also include a quantitative element), the three-week period that was idealised as the total length of the focus group process, the mindset that participants should adopt and the freedom they would have to interact and, particularly, to discuss the posed topics.

A second message was then sent to the participants that included a set of conceptualisations and possible initial assumptions (ex: what are 'low-density regions', the current trends in both tourism and regional development etc.), a challenging sentence aimed at triggering the participants' discussion, and the indication that the participants in the focus group should be contacted through (i) an e-mail message with all experts included in the recipients and (ii) an online forum platform especially 


\begin{tabular}{|c|c|c|c|c|c|c|c|c|c|c|}
\hline & & & & & & xper & & & & \\
\hline & & 1 & 2 & 3 & 4 & 5 & 6 & 7 & 8 & 9 \\
\hline Education & Bachelor & & & & & & $\bar{x}$ & $\bar{x}$ & & \\
\hline & Master & & & & & & & & $x$ & $x$ \\
\hline & $\mathrm{PhD}$ & $\mathbf{x}$ & $x$ & $x$ & $\mathrm{x}$ & $\mathbf{x}$ & & & & \\
\hline Prof. group & academic/researcher & $\mathbf{x}$ & & $x$ & $\mathrm{x}$ & $\mathbf{x}$ & & & & \\
\hline & public sector & & & & & & $\mathbf{x}$ & $\mathbf{x}$ & & \\
\hline & private sector & & $\mathbf{x}$ & & & & & & $\mathbf{x}$ & $\mathbf{x}$ \\
\hline Prof. experience & $0-5$ & & & & & & & & & \\
\hline & $5-10$ & & $\mathbf{x}$ & & & & & & $x$ & \\
\hline & $>10$ & $\mathrm{x}$ & & $x$ & $\mathbf{x}$ & $\mathbf{x}$ & $x$ & $\mathbf{x}$ & & $x$ \\
\hline
\end{tabular}

Bachelor - Bachelor's degree; Master - Master's degree; PhD - Doctorate degree.

developed for this study. After this initial stage, and as a set of replies were being exchanged between the focus group participants, the moderators then presented some additional discussion points, hence ensuring that the topics surrounding the study were always the centre of discussion [90].

As the interaction between participants evolved, the focus group moderators started posing questions that would serve the purpose of directing the discussion towards the use of VR technologies as a means to improve tourism in regions with low-economic and social development. The questions posed where the following:

- Is it possible to perceive the incorporation of technologies in the tourism sector to help tourism operators develop their products and services?

- Are tourists, including those seeking tourism products located in rural regions, transforming themselves into 'digital tourists'?

- What do you think of the potential use of VR systems and applications in tourism? If so, what are your main concerns?

- Do you think that these technologies could be applied to tourism in low-density regions? If so, what are your main concerns?

As the discussion became more assertive and, in a global manner, consensual, the focus group moderators started directing the discussion towards the possible factors leading to the adoption of VR technologies by tourism operators. Hence, they supplied the focus group participants with a list of previously identified variables that might be associated with the adoption of $\mathrm{VR}$, and posed the following questions:

- From the set of variables in the supplied list what would be the most relevant to the referred adoption process?

- Do you believe that further analysis (possibly by the implementation of a quantitative study) might be advised in order to understand VR adoption by tourism operators?

- What are your thoughts on the possible differences in the triggers behind VR adoption by tourism operators that have business activity in urban/littoral territories and those who have businesses in low-density regions?

This final part of the focus group was the one in which the participants had the most interesting debate as, despite the existence of a perceivable consensus on the need for further validation on the triggers behind VR adoption by tourism operators, some argued that this adoption process would have specificities regarding the location in which the technology was being applied. Furthermore, some argued that considering the broader use of the technology and its innovative aspect, the adoption process would be similar in both urban and rural environments.

As the discussion reached the three-week period deadline, the moderators announced the end of the study and presented a formal appreciation for the participants' efforts.

\subsection{Focus group - global considerations}

During a three-week period, the focus group experts were triggered by the research team to give their opinions and actively discuss each other's opinions on the previously mentioned research acknowledgments.

After the three-week period the focus group experts reached the following assumptions:

- The digital transformation of tourism is something completely accepted not only by the academic/research community but also (and most importantly) by national regulators, tourism operators and, of course, by tourists.

- The current tourist experience is totally different from that which existed half a decade ago. Tourists now enjoy destinations that they visit by using a set of digital devices (smartphone, tablet or digital cameras, including also video recording devices in all conditions (e.g. GoPro) and virtual and augmented reality glasses), that totally transform their experience to the point of making it not only much more immersive and complete but also something where memory becomes much more realistic and characterising of the visited destination.

- VR in all its forms (fully virtual, augmented, mixed or multisensory), is now accepted as a technology of the future that allows its users a more immersive interaction and, above all, delocalised in time and space.

- The use of VR technologies in the development of a more complete and more attractive tourist experience that allows tourists to have a more detailed perception about a certain tourist destination is seen, globally, as something very positive and that can bring added value for tour operators and, in parallel, for the territories.

- Acknowledging the transformation of the tourism destination into something eminently intelligent and with the ability to provide almost individual responses to its visitors (i.e. the rising of 'smart destinations'), one perceives as being clearly important - to be analysed and understood, in detail - the determinants of adopting innovative and disruptive solutions, such as VR, in the context of tourism operators and, ultimately, in the context of the tourists themselves.

- Although the multiplicity of possible determinants of VR technology adoption at the organisational level represents a highly broad view on the topic, it is not totally clear their acknowledgement and perception by tourism operators. With this in mind, it is clearly relevant to develop a set of conceptual adoption models that, together with an empirical validation focused on a broad target group of tourism operators, allows to infer assumptions about which determinants are most relevant to the adoption process.

- Assuming the existing considerations in the scientific and technical literature and in the various National and International reports on the subject, it becomes clear that the economically disadvantaged territories have their own characteristics that do not allow their direct comparison with the more developed tourist destinations and it is, therefore, necessary that the process 
of ascertaining the impacts of each of the identified determinants takes into account this reality.

\section{Conclusions}

Tourism is one of the economic activities whose evolution and impact on the territories which incorporate it has been the most significant in the last decade. As far as Portugal is concerned, tourism indicators are incredibly positive, thus having a very relevant impact on the economic and structural development of the sector and, most importantly, on the social and economic evolution of tourist destinations.

The digital transformation that is present throughout today's society (very much known as the 'digital society' or 'knowledge society'), is also very much present in tourism, with the concept of 'smart tourism' becoming a complete reality and it is very common to have the real-time integration of highly innovative technological solutions with the tourist and with their tourism experience.

It is clear the existing efforts to combine VR technologies with the tourism sector (to plan and develop tourist experiences and to execute highly innovative tourism promotion initiatives), aimed at capturing a greater audience in a highly competitive market, in the light of our present knowledge, there is not a valid conceptualisation of the factors whose impact is most determinant to the process of adopting the aforementioned technologies, both at the level of tourists and at the tourism operators level.

Even though VR adoption by tourists is immensely relevant, this is a work area that has already been somewhat developed by the scientific community, thus possessing some truly interesting initial perspectives. As we could acknowledge by analysing the existing literature, the process of VR adoption by tourism operators is yet to be the target of a comprehensive study. With this in mind, a systematic analysis of the existing literature was carried out, aimed at identifying a wide set of possible determinants of the referred adoption process. The analysis performed allowed us to identify 42 possible determinants whose impact may be relevant for the adoption of VR by tourism operators and for the development of new (more innovative and more adapted to the desires of tourists) tourism products.

Assuming the multiplicity of perspectives in the VR adoption theme and the impact that this process can have on tourism destinations (especially in low-density and economically disadvantaged territories), we performed a focus group supported by digital technologies. The focus group was based on a delocalised and not always synchronous discussion, which allowed us to join together a group of experts in the themes inherent to the use of technology in tourism and consequently allowed us to obtain a set of more complete and assertive inferences on the subject. This focus group has clearly shown that the creation of a more innovative tourism offering, based on recent digital technologies, such as VR, will enable tourism destinations to become more attractive to new tourists and consequently improve tourism destinations' economic and social development.

\subsection{Limitations and future work}

This work presents a very relevant contribution to science, through the identification and systematisation of a set of possible determinants of the adoption of VR by tour operators or by organisations; and through the knowledge obtained via the focus group in order to adapt the touristic supply to those who are looking for a more immersive and digital touristic experience. However, these contributions are not definitive due to the inexistence of a conceptual model regarding the adoption of VR by tourism operators and the lack of an inherent empirical validation, through a questionnaire to a wide set of operators, which is also a limitation of the present work and something which we intend to work on soon.

Therefore, future work will be the empirical validation of the perceived impact of the determinants of the adoption of technologies identified for touristic supply, where the destinations are economically disadvantaged and low-density territories.

\section{Acknowledgments}

This work was financed by the ERDF - European Regional Development Fund through the Operational Programme for Competitiveness and Internationalisation - COMPETE 2020 Programme and by the National Funds through the Portuguese funding agency, FCT - Fundação para a Ciência e a Tecnologia within project POCI-01-0145-FEDER-031309 titled "PromoTourVR - Promoting Tourism Destinations with Multisensory Immersive Media.

\section{References}

[1] Oh, C.: 'The contribution of tourism development to economic growth in the Korean economy', Tour. Manage., 2005, 26, pp. $39-44$

[2] INE: 'Estatistica do turismo - 2017 instituto nacional de estatística', 2018

[3] Buhalis, D., O'Connor, P.: 'Information communication technology revolutionizing tourism', Tour. Recreat. Res., 2005, 30, pp. 7-16

[4] Martins, J., Gonçalves, R., Branco, F., et al: 'A multisensory virtual experience model for thematic tourism: A port wine tourism application proposal', J. Destinat. Mark. Manoge., 2017, 6, pp. 103-109

[5] Yung, R, Khoo-Lattimore, C.: New realities: a systematic literature review on virtual reality and augmented reality in tourism research', Current Issues Tour., 2019, 22, pp. 2056-2081

[6] Stamboulis, Y., Skayannis, P.: 'Innovation strategies and technology for experience-based tourism', Tour. Manage., 2003, 24, pp. 35-43

[7] Khan, A., Keung, J.: 'Systematic review of success factors and barriers for software process improvement in global software development', IET Softw., 2016, 10, pp. 125-135

[8] Salo, O., Abrahamsson, P.: 'Agile methods in european embedded software development organisations: a survey on the actual use and usefulness of extreme programming and scrum', IET Softw., 2008, 2, pp. 58-64

[9] Gonçalves, R., Martins, J., Pereira, J., et al.: 'Promoting e-commerce software platforms adoption as a means to overcome domestic crises: the cases of Portugal and Spain approached from a focus-group perspective', in 'Trends and applications in software engineering' (Springer, Basel, Switzerland, 2016), pp. 259-269

[10] Nguyen, T., Newby, M., Macaulay, M.: 'Information technology adoption in small business: confirmation of a proposed framework', J. Small Business Manage., 2015, 53, pp. 207-227

[11] Martins, J., Gonçalves, R, Pereira, J., et al.: 'Social networks sites adoption at firm level: A literature review'. 2014 9th Iberian Conf. on Information Systems and Technologies (CISTI), Barcelona, Spain, 2014, pp. 1-6

[12] Oliveira, T., Martins, M.: 'Literature review of information technology adoption models at firm level', Electron. J. Inf. Syst. Evaluat., 2011, 14, p. 110

[13] Bhattacherjee, A., Premkumar, G.: "Understanding changes in belief and attitude toward information technology usage: $A$ theoretical model and longitudinal test', $M S S Q ., 2004,28$, (2), pp. 229-254

[14] Wu, L., Chiu, M.: 'Organizational applications of IT innovation and firm's competitive performance: A resource-based view and the innovation diffusion approach', J. Eng. Technol Manage., 2015, 35, pp. 25-44

[15] Venkatraman, N.: 'IT-enabled business transformation: from automation to business scope redefinition', Sloan Manage. Rev., 1994, 35, pp. 73-73

[16] Markus, M.L., Keil, M.: 'If we build it, they will come: designing information systems that people want to use', J. Res. Comput. Education, 1994, 35, p. 11

[17] Malhotra, Y., Galletta, D.F.: 'Building systems that users want to use', Commun. $A C M, 2004,47$, pp. 88-94

[18] Cardoso, L., Martins, J., Goncalves, R, et al.: "A proposal for an electronic negotiation platform for tourism in low-density regions: characterizing a functional analysis and prototype for the douro valley'. Int. Conf. on Software Process Improvement, Guadalajara, Mexico, 2018, pp. 280-292

[19] Blili, S., Raymond, L.: 'Information technology: threats and opportunities for small and medium-sized enterprises', Int. J. Inf. Manage, 1993, 13, pp. 439448

[20] Gonçalves, R., Martins, J., Branco, F., et al:: 'Increasing the reach of enterprises through electronic commerce: $A$ focus group study aimed at the cases of Portugal and Spain', Comput. Sci. Inf. Syst, 2016, 13, (3), pp. 36-36

[21] Martins, J., Costa, C., Oliveira, T., et al:: 'How smartphone advertising influences consumers' purchase intention', J. Bus. Res., 2019, 94, pp. 378387

[22] Parrilla, J., Font, A., Nadal, J.: "Tourism and long-term growth a spanish perspective', Ann. Tour. Res., 2007, 34, pp. 709-726

[23] Gancía, F., Vázquez, A., Macias, R.: 'Resident's attitudes towards the impacts of tourism', Tour. Manage. Perspect., 2015, 13, pp. 33-40

[24] Basu, P.: 'Is sustainable tourism development possible? Broad issues concerning Australia and Papua New Guinea', in 'Tourism and economic development' (Routledge, Abingdon, UK, 2017), pp. 140-149

[25] Boes, K., Buhalis, D., Inversini, A.: 'Smart tourism destinations: ecosystems for tourism destination competitiveness', Int. J. Tour. Cities, 2016, 2, pp. 108124

[26] Jovicic, D.: 'From the traditional understanding of tourism destination to the smart tourism destination', Current lssues Tour, 2019, 22, pp. 276-282

[27] Ferreira, M., Moreira, F., Seruca, I.: 'Digital transformation towards a new context of labour: enterprise 4.0', in 'Technological developments in industry 4.0 for business applications' (IGI Global, Hershey, USA, 2019), pp. 26-49

[28] Moreira, F., Ferreira, M., Seruca, I.: 'Enterprise 4.0 - the emerging digital transformed enterprise?', Procedia Comput. Sci., 2018, 138, pp. 525-532 
[29] $\mathrm{Da} \mathrm{Xu}, \mathrm{L} ., \mathrm{He}, \mathrm{W} ., \mathrm{Li}, \mathrm{S}$. .: 'Internet of things in industries: A survey', IEEE Trans. Ind. Inf., 2014, 10, pp. 2233-2243

[30] Gretzel, U., Sigala, M., Xiang, Z, ef al.: 'Smart tourism: foundations and developments', Electron. Mark, 2015, 25, pp. 179-188

[31] Gretzel, U., Werthner, H., Koo, C., et al.: 'Conceptual foundations for understanding smart tourism ecosystems', Comput. Human Behov., 2015, 50, pp. 558-563

[32] Buhalis, D., Amaranggana, A.: 'Smart tourism destinations enhancing tourism experience through personalisation of services', in 'Information and communication technologies in tourism 2015' (Springer, Basel, Switzerland, 2015), pp. 377-389

[33] Kastenholz, E., Cameiro, M., Marques, C., et al.: "Understanding and managing the rural tourism experience - the case of a historical village in Portugal', Tour. Manage. Perspect., 2012, 4, pp. 207-214

[34] Pereira, A., Martins, J., Branco, F., et al.: 'Determinants of the adoption of augmented reality by tour operators in disadvantaged economic regions'. 2018 13th Iberian Conf. on Information Systems and Technologies (CISTI), Caceres, Spain, 2018, pp. 1-7

[35] Cánoves, G., Villarino, M., Priestley, G., et al.: 'Rural tourism in Spain: an analysis of recent evolution', Geofonom, 2004, 35, pp. 755-769

[36] Roca, Z., Oliveira-Roca, M.: 'Affirmation of territorial identity: A development policy issue', Land. use. policy., 2007, 24, pp. 434-442

[37] Sidali, K, Kastenholz, E., Bianchi, R.: 'Food tourism, niche markets and products in rural tourism: combining the intimacy model and the experience economy as a rural development strategy', J. Sustain. Tour, 2015, 23, pp. 1179-1197

[38] Silva, L.: 'Os impactos do turismo em espaço rural', Antropologia Portuguesa, 2006, 22, pp. 295-317

[39] Teixeira, S., Branco, F., Martins, J., et al.: "Main factors in the adoption of digital marketing in startups an online focus group analysis'. 2018 13th Iberian Conf. on Information Systems and Technologies (CISTI), Caceres, Spain, 2018, pp. 1-5

[40] Schuemie, M., Van Der Stragten, P., Krijn, M., et al.: 'Research on presence in virtual reality: A survey', Cyberpsychol Behav, 2001, 4, pp. 183-201

[41] Guttentag, D.A.: 'Virtual reality: applications and implications for tourism', Tour. Manage., 2010, 31, pp. 637-651

[42] Waltemate, T., Gall, D., Roth, D., et al: 'The impact of avatar personalization and immersion on virtual body ownership, presence, and emotional response', IEEE Trans. Vis. Comput. Graphics, 2018, 24, pp. 1643-1652

[43] Moorhouse, N., Jung T, tom Dieck, M.C. 'Tourism marketers perspectives on enriching visitors city experience with augmented reality: an exploratory study', in 'Augmented reality and virtual reality' (Springer, Basel, Switzerland, 2019), pp. 129-144

[44] Vishwakarma, P., Mukherjee, S., Datta, B.: 'Antecedents of adoption of virtual reality in experiencing destination: A study on the Indian consumers', Tour. Recreat. Res., 2020, 45, pp. 42-56

[45] tom Dieck, M., Jung, T.: 'A theoretical model of mobile augmented reality acceptance in urban heritage tourism', Curnent Issues Tour., 2018, 21, pp. 154-174

[46] Paulo, M., Rita, P., Oliveira, T., et al.: 'Understanding mobile augmented reality adoption in a consumer context', J. Hosp. Tour. Technol, 2018, 9, pp. 142-157

[47] $\mathrm{He}, \mathrm{Z}$., Wu, L., Li, X.: 'When art meets tech: the role of augmented reality in enhancing museum experiences and purchase intentions', Tour. Manage., 2018, 68, pp. 127-139

[48] Keele, S.: 'Guidelines for performing systematic literature reviews in software engineering'. Technical report, Ver. 2.3 EBSE Technical Report. EBSE, 2007

[49] Hua, G., Haughton, D.: 'Virtual worlds adoption: A research framework and empirical study', Online Inf. Rev., 2009, 33, pp. 889-900

[50] Rese, A., Baier, D., Geyer-Schulz, A. et al.: 'How augmented reality apps are accepted by consumers: A comparative analysis using scales and opinions', Technol. Fonecast. Soc. Change, 2017, 124, pp. 306-319

[51] Sabi, H., Uzoka, F., Langmia, K, et al.: 'A cross-country model of contextual factors impacting cloud computing adoption at universities in sub-saharan Africa', Inf. Syst. Front., 2018, 20, pp. 1381-1404

[52] Ali, O., Soar, J., Shrestha, A.: 'Perceived potential for value creation from cloud computing: a study of the Australian regional government sector', Behav. Inf. Technol., 2018, 37, pp. 1157-1176

[53] Ramayah, T., Ling, N., Taghizadeh, S., et al: 'Factors influencing SMEs website continuance intention in Malaysia', Telemat. Inform., 2016, 33, pp. 150-164

[54] Alkhater, N., Walters, R., Wills, G.: "An empirical study of factors influencing cloud adoption among private sector organisations', Telemat. Inform., 2018, 35, pp. 38-54

[55] Martins, J., Gonçalves, R., Oliveira, T., et al:: 'Understanding the determinants of social network sites adoption at firm level: A mixed methodology approach', Electron. Comm. Res. Applic., 2016, 18, pp. 10-26

[56] Numes, S., Martins, J., Branco, F., et al.: 'An online focus group approach to e-government acceptance and use'. World Conf. on Information Systems and Technologies, Naples, Italy, 2018, pp. 449-456

[57] Alsaad, A., Mohamad, R, Ismail, N.: "The moderating role of trust in business to business electronic commerce (B2B EC) adoption', Comput. Hum. Behav., 2017, 68, pp. 157-169

[58] Gangwar, H, Date, H., Ramaswamy, R. 'Understanding determinants of cloud computing adoption using an integrated TAM-TOE model', $J$. Enterp. Inf. Manag., 2015, 28, pp. 107-130

[59] Cranmer, E., Jung, T., tom Dieck, M., et al.: 'Understanding the acceptance of augmented reality at an organisational level: the case of geevor tin mine museum', in 'Information and communication technologies in tourism 2016' (Springer, Basel, Switzerland, 2016), pp. 637-650
[60] Pura, M.: "Linking perceived value and loyalty in location-based mobile services', Manag. Serv. Qual., Int. J., 2005, 15, pp. 509-538

[61] Lee, H.G., Chung, S., Lee, W.-H.: 'Presence in virtual golf simulators: the effects of presence on perceived enjoyment, perceived value, and behavioral intention', New Media Soc., 2013, 15, pp. 930-946

[62] Jung, T., Chung, N., Lewe, M.: 'The determinants of recommendations to use augmented reality technologies: the case of a Korean theme park', Tour. Manage., 2015,49 , pp. $75-86$

[63] Martins, J., Branco, F., Gonçalves, R, et al:: 'Assessing the success behind the use of ectucation management information systems in higher ectucation', Telemat. Inform., 2018, 38, pp. 182-193

[64] Harris, I., Wang, Y., Wang, H.: 'ICT in multimodal transport and techmological trends: unleashing potential for the future', Int. J. Prod. Econ., 2015, 159, pp. 88-103

[65] Rauschnabel, P, Ro, Y.: 'Augmented reality smart glasses: an investigation of technology acceptance drivers', Int. J. Technol. Market, 2016, 11, pp. 123148

[66] Awa, H., Ojiabo, O., Emecheta, B.: 'Integrating TAM, TPB and TOE frameworks and expanding their characteristic constructs for e-commerce adoption by SMEs', J. Sci. Technol. Policy Manage., 2015, 6, pp. 76-94

[67] Chandra, S., Kumar, K.: 'Exploring factors influencing organizational adoption of augmented reality in e-commerce: empirical analysis using technology-organization-environment model', J. Electron. Commerce Res., 2018,19 , pp. 237-265

[68] Mohammed, F., Ibrahim, O., Nilashi, M., et al.: 'Cloud computing adoption model for e-government implementation', Inf. Dev., 2017, 33, pp. 303-323

[69] Oliveira, T., Thomas, M., Espadanal, M.: 'Assessing the determinants of cloud computing adoption: an analysis of the manufacturing and services sectors', Inf. Manage., 2014, 51, pp. 497-510

[70] Aboelmaged, M.: 'Predicting e-readiness at firm-level: an analysis of technological, organizational and environmental (TOE) effects on emaintenance readiness in manufacturing firms', Int. J. Inf. Manage, 2014, 34, pp. 639-651

[71] Wang, Y., Wang, Y.: 'Determinants of firms' knowledge management system implementation: an empirical study', Comput. Fim. Behav, 2016, 64, pp. 829-842

[72] Rodrigues, S., Goncalves, R., Teixeira, M., et al.: 'Bidirectional e-commerce platform for tourism in low-density regions: the douro valley case study'. 2018 13th Iberian Conf. on Information Systems and Technologies (CISTT), Caceres, Spain, 2018, pp. 1-5

[73] Shiau, S., Huang, C., Yang, C., et al.: 'A derivation of factors influencing the innovation diffusion of the OpenStreetMap in STEM education', Sustainability, 2018, 10, p. 3447

[74] Kourouthanassis, P., Boletsis, C., Bardaki, C., ef al.: 'Tourists responses to mobile augmented reality travel guides: the role of emotions on adoption behavior', Pervasive Mob. Comput., 2015, 18, pp. 71-87

[75] Wang, Y., Kung, L., Byrd, T.: 'Big data analytics: understanding its capabilities and potential benefits for healtheare organizations", Technol. Forecast. Soc. Change, 2018, 126, pp. 3-13

[76] Li, H., Wu, J., Gao, Y., ef al:: 'Examining individuals' adoption of healthcare wearable devices: an empirical study from privacy calculus perspective', Int. J. Med. Inform., 2016, 88, pp. 8-17

[77] Siamagka, N., Christodoulides, G., Michaelidou, N., ef al: 'Determinants of social media adoption by B2B organizations', Ind. Mark. Manage., 2015, 51, pp. 89-99

[78] Hollenstein, H.: 'Determinants of the adoption of information and communication technologies (ICT): an empirical analysis based on firm-level data for the Swiss business sector', Struct. Change Econ. Dyn., 2004, 15, pp. 315-342

[79] Lin, H.: 'Understanding the determinants of electronic supply chain manggement system adoption: using the technology-organizationenvironment framework', Technol. Forecast. Soc. Change, 2014, 86, pp. 8092

[80] Ramdani, B., Chevers, D., Williams, D.A.: 'SMEs' adoption of enterprise applications: A technology-organisation-environment model', J. Small Business Enterprise Dev, 2013, 20, pp. 735-753

[81] Hein, D., Rauschnabel, P.: 'Augmented reality smart glasses and knowledge management: A conceptual framework for enterprise social networks', in Rossmann, A., Stei, G., Besch, M. (Eds.): 'Enterprise social networks' (Springer Gabler, Wiesbaden, 2016), pp. 83-109

[82] Aminah, S., Ditari, Y., Kumaralalita, L., et al.: 'E-procurement system success factors and their impact on transparency perceptions: perspectives from the supplier side', Electron. Gov., Int. J., 2018, 14, pp. 177-199

[83] Kim, D., Hebeler, J., Yoon, V., et al.: 'Exploring determinants of semantic web technology adoption from IT professionals' perspective: industry competition, organization innovativeness, and data management capability", Comput. Hum. Behav., 2018, 85, pp. 18-33

[84] Gonçalves, R., Martins, J., Pereira, J., et al.: 'Accessibility levels of Portuguese enterprise websites: equal opportumities for all?', Behav. Inf. Technol., 2012, 31, pp. 659-677

[85] Sutton, S., Amold, V.: 'Focus group methods: using interactive and nominal groups to explore emerging technology-driven phenomena in accounting and information systems', Int. J. Account. Inf. Syst., 2013, 14, pp. 81-88

[86] Bell, E., Bryman, A., Harley, B.: 'Business research methods' (Oxford university press, Oxford, UK, 2018)

[87] Kenny, A.: 'Interaction in cyberspace: an online focus group', $J$. Adv. Nurs., 2005, 49, pp. 414-422

[88] Reid, D., Reid, F.: 'Online focus groups: an in-depth comparison of computermediated and conventional focus group discussions: an in-depth comparison of computer-mediated and conventional focus group discussions', Int $J$. Market Res., 2005, 47, pp. 131-162 
[89] Vaportzis, E., Giatsi Clausen, M., Gow, A.J.: 'Older adults perceptions of technology and barriers to interacting with tablet computers: a focus group study', Front. Psychol., 2017, 8, p. 1687
[90] Gonçalves, R., Martins, J., Pereira, J., et al:: 'Enterprise web accessibility levels amongst the forbes 250: where art thou o virtuous leader?', J. Bus. Ethics., 2013, 113, pp. 363-375 